\title{
Corpolinguagem e o não limite da palavra no insulto*1
}

\author{
Glória Maria Monteiro de Carvalho*2 \\ Maria de Fátima Vilar de Melo*3
}

\begin{abstract}
Tomamos, como ponto de partida deste artigo, o conceito de violência estrutural (Lebrun, 2002), isto é, a violência da linguagem que nos constitui como seres humanos. No mundo contemporâneo, a negação desse tipo de violência produziu uma violência suplementar que passa, necessariamente, pela carência da palavra. A análise de uma situação - querela entre lavadores de carros - forneceu indicações sobre uma maneira de atuação da violência suplementar, desfazendo os efeitos simbólicos produzidos pela violência estrutural, ou seja, desfazendo os limites instituídos pela linguagem.
\end{abstract}

Palavras-chave: Linguagem, insulto, violência estrutural, carência da linguagem

*1 Trabalho apresentado como simpósio no Colóquio Internacional sobre Metapsicologia da Perversão. Usos Sociais da Perversão, realizado na Universidade Católica de Pernambuco, Recife/PE, em parceria com a Université Catholique de l'Ouest - Angers - França, no período de 26 a 28 de agosto de 2013.

*2 Universidade Católica de Pernambuco - Unicap (Recife, PE, Br).

*3 Universidade Católica de Pernambuco - Unicap (Recife, PE, Br). 


\section{Introdução}

O interesse pelo tema e a necessidade de colocá-lo em discussão originaram-se de uma situação onde se destaca a escuta de palavrões insultuosos vociferados por lavadores de carros que se agrupavam em um terreno baldio de um bairro tradicional da cidade de Recife, Brasil.

Muito embora pareça, a princípio, natural o emprego do termo insulto para essas situações, a pertinência desse emprego será colocada em questão ao longo desse trabalho. Assim começamos pela definição desse termo.

No dicionário Houaiss (2001) encontramos a seguinte definição para insulto: "ataque verbal ofensivo, injuria"; e a palavra insultar é definida como: "proferir palavras ou ter comportamento que atinge gravemente a dignidade, a honra de, afrontar, ofender" (p. 427).

$\mathrm{O}$ insulto é o avesso da linguagem polida ligada à cortesia e, portanto, à civilidade, como nos diz Sérgio Buarque de Holanda, em seu livro Raizes do Brasil, ao falar da cordialidade do brasileiro, distinguindo-a da cortesia: "na cortesia, na civilidade, há qualquer coisa de coercitivo - ela pode exprimir-se em mandamentos e sentenças (...)" (2009, p. 147). Na mesma página, um pouco adiante, ele acrescenta: "Por meio de semelhante padronização das formas exteriores da cordialidade, que não precisam ser legítimas para se manifestarem, revela-se um decisivo triunfo do espírito sobre a vida".

No campo da linguística, o insulto encontra-se relacionado, de maneira geral, a uma forma de emprego de linguagem torpe, também chamada de disfêmica. Segundo Dal Corno (2010), com 
base em Allan \& Burridge (2006), as expressões disfêmicas envolvem palavrões ou outras formas de comentário que depreciam, sendo endereçados a outros, com o propósito de insultá-los ou feri-los. Assim, longe de representarem o "triunfo do espírito sobre a vida", essas palavras possuem forte carga emocional e estão presentes na maioria das línguas, mesmo que essa presença varie de acordo com o tempo e o lugar, como assinala Pinker (2008). Com o objetivo de caracterizar esse tipo de linguagem no campo da linguística, esse autor acrescenta que:

Sejam elas chamadas de xingamentos, palavrões, baixo calão, profanidade, obscenidade, indecência, vulgaridade, blasfêmia (...); como palavras sujas (...) ou tabus; ou como termos ruins, rudes, grosseiros, vis (...), essas expressões suscitam muitas vezes enigmas para quem estiver interessado na língua como janela para a natureza humana. (p. 376)

Dal Corno (2010) assinala que alguns autores nesse campo (como, por exemplo, Tartamella, 2006, Hughes, 1998) concordam que além de ofensa, a linguagem disfêmica pode causar outros efeitos desagradáveis como perturbação no discurso, expressão de revolta etc. Mas, por outro lado, os autores observam que esse tipo de linguagem pode também indicar familiaridade e descontração, podendo, inclusive, introduzir um elemento jocoso no diálogo. É preciso ressaltar, porém, que esses efeitos não concernem ao insulto.

Muito embora, como já assinalamos, o insulto consista no avesso da cortesia, paradoxalmente, ele estaria na origem da civilização, conforme propõe Freud (1893/2006a) ao fazer referência ao que disse um autor inglês, que ele não nomeia:

O primeiro homem a desfechar contra seu inimigo um insulto, em vez de uma lança, foi o fundador da civilização. Portanto, as palavras são substitutas da ação e, em alguns casos, (por exemplo, na confissão) as únicas. (p. 45)

Destacamos, nessa proposta de Freud, a possibilidade de a palavra substituir o ato e um ato de natureza violenta, ou seja, a linguagem possui a função de conter a violência, uma vez que ela se coloca como mediadora na relação do homem com o mundo.

Ao tratarmos o insulto na sua relação com a violência, indagamos, contudo: que violência queremos discutir? Essa pergunta, assim colocada, supõe que há tipos diferentes de violência. Para fazer a distinção necessária entre esses tipos, recorremos ao artigo de Jean-Pierre Lebrun (2002), Une logique d'enfer (Uma lógica infernal), que traz uma discussão sobre a violência dos jovens, nos dias de hoje, em diferentes espaços: na escola, na família ou mesmo na rua. Nesse artigo, o autor levanta a hipótese de que essa violência não concerniria à violência própria ao conflito entre gerações que encontramos desde sempre, e sim a uma violência fora 
de conflito, a uma violência que tem muito mais a ver com o ato de evitar o conflito ou até mesmo com a impossibilidade de com ele se confrontar.

A primeira violência seria relativa à violência estrutural, que estaria ligada ao fato de que o ser humano é um ser doente da palavra. Para o autor essa é "uma violência fundamental, de estrutura, é a da linguagem que nos define como humanos" (Lebrun, 2002). ${ }^{1}$ Tal violência, que implica a linguagem, está ligada ao interdito do incesto, implicando, portanto, uma perda, uma renúncia que cada um deve fazer para se constituir como sujeito. De maneira que essa violência não pode ser simplesmente eliminada, porque isso significaria a eliminação do humano; muito pelo contrário, ela deve encontrar seu lugar no interior do sujeito. A segunda violência diz respeito a uma violência suplementar, que vem crescendo no mundo contemporâneo em função da negação da violência estrutural. Este tipo de violência é efeito da carência da linguagem.

Vale assinalar que muito embora tenhamos conhecimento de textos posteriores de Lebrun $(2008,2010)$, onde ele desenvolveu alguns pontos presentes nesta discussão, a nossa escolha pelo artigo referido justifica-se pela divisão esquemática e clara que ele traz dos dois tipos de violência.

\section{Formas de atualização da violência estrutural}

Destacamos, então, que o ódio que nos habita, como uma condição de nossa humanidade, encontra seus limites por meio da palavra, do simbólico. Por sua vez, a inauguração do simbólico não ocorreria com tranquilidade, ou de forma pacífica, mas implicaria atos de violência que Lebrun (2002) nomeia, como vimos, violência estrutural ou, de acordo com Lacan (1975), violência simbólica.

Nesse sentido, diz Lacan:

Há um abismo entre a relação com o latido e o fato de que, afinal, o ser humilhado, o ser humus, o ser humano, o ser, como vocês queiram chamá-lo - trata-se de você e de mim -, que o ser humano chega a dizer alguma coisa. Não somente a poder dizer, mas este cancro que eu defini como sendo a linguagem, porque eu não sei como o chamar de outra maneira, esse cancro que é a linguagem implica desde o início uma espécie de sensibilidade. (p. 6)

${ }^{1}$ Recuperado em 10 ago.2013 de <http.//www.freud-lacan.com/articles/articlephp? id_article $=00418>$. 
Em consonância com essa afirmação de Lacan, Lebrun (2002) assinala violência estrutural se atualiza de diversas maneiras, sendo uma delas as primeiras palavras da mãe diante de seu filho, supondo, nele, um saber que, entretanto, é limitado àquilo que ela percebe, consistindo assim numa forçagem. Nessa mesma linha, Bergès e Balbo $(2001 ; 2002)$ referem-se a um golpe de força, propondo que, diante de expressões do corpo da criança, a mãe formula uma hipótese sobre um saber que a criança teria, isto é, a mãe antecipa, faz uma hipótese de que seu filho compreende o que ela diz, havendo a suposição de que a própria criança seria capaz de formular hipóteses. Vários autores atribuem então especial realce a esse golpe de força (Didier Weill, 1999; Laberge, 2008).

No âmbito da investigação da trajetória linguística da criança, Lemos (2008), através do seu texto "Da angústia na infância", destaca a resistência que a criança, concebida como corpo pulsional, opõe à sua captura pelo significante. Segundo essa autora, uma tal captura implica conflito - conflito a esperar do embate entre heterogêneos: corpo e linguagem. Esse conflito (ou embate) não se dá a ver, ficando oculto se, durante a sua trajetória linguística, a criança não se depara com uma dificuldade que produza efeitos de obstáculo a essa trajetória. Tudo aconteceria, conforme realça a autora citada, como se a criança seguisse um percurso suave (cor de rosa) que não daria visibilidade àquele embate inicial o qual pode, contudo, ser indicado através das falhas nas produções verbais infantis. A esse respeito, podemos pensar, com fundamento em Leite (2003), que o funcionamento da linguagem como estrutura consiste numa rede de inibições e, acrescentaríamos, uma rede de inibições implantada (não sem violência) num corpo.

No entanto, retomando o texto de Lebrun (2002), mais valem as palavras limitadas de uma mãe, que uma ausência de palavras. Por sua vez, na relação mãe-filho, a interposição do pai, introduzindo a alteridade, consiste numa ruptura e, portanto, numa violência. $\mathrm{O}$ sentido dessas formas de atualização da violência primordial constitutiva da identidade humana reside, sobretudo, no reconhecimento de que existem lugares diferentes e, como consequência, no reconhecimento e legitimação da autoridade, em virtude da instauração do simbólico.

\section{A carência da palavra e a emergência de uma violência suplementar}

Lebrun (2002) observa que a autoridade - decorrente do reconhecimento de que existem lugares diferentes - encontra-se hoje inteiramente subvertida, não possuindo mais legitimidade para servir de suporte ao confronto, engendrando, portanto, a desistência dos mais velhos de ocupar seu lugar. Como consequência dessa subversão, os jovens não possuem mais interlocutores a quem endereçar sua violência. Nega-se, 


\section{ARTIGOS}

desse modo, a violência estrutural, o que vai produzir, de forma paradoxal, uma violência suplementar, essa que vivemos/conhecemos hoje. Assim, diríamos que, para esse autor, a origem da violência que estamos vivendo, no mundo contemporâneo, passa, necessariamente, pelo que ele denomina a carência da palavra.

Retomamos aqui o que diz Lebrun (2002) sobre a violência suplementar: "nós pensamos que ela tem a ver com uma violência fora do conflito, a uma violência que nasceria menos de um enfrentamento do que da evitação, ou mesmo da impossibilidade de uma confrontação" (tradução nossa). ${ }^{2}$

Recortamos, nessa citação, a impossibilidade de haver um confronto o qual requer que as partes implicadas ocupem uma posição determinada e que haja um endereçamento.

Destacamos que essa ideia alinha-se, estreitamente, a Lacan, quando diz: "Ali onde a palavra se desfaz, começa a violência" (citado por Lebrun, 2002, tradução nossa). ${ }^{3}$ Podemos lembrar também que essa ideia ecoa em autores oriundos de diferentes campos (Filosofia, Sociologia, Psicanálise, História, Antropologia) que vêm estudando os fenômenos da contemporaneidade. Alguns desses autores têm investigado/discutido, particularmente, os efeitos da ordem do neoliberalismo sobre a ordem social, entre os quais, podemos citar: Agamben (2004, 2009), Bauman (2001, 2004, 2009, dentre outros), Dufour $(2007,2009)$. Por sua vez, conforme já foi destacado por vários autores, neste Colóquio, diferentes escolas da psicanálise têm também realizado essa discussão.

É importante ainda lembrar que a concepção de insulto inclui o endereçamento. Nesse sentido, a linguística discrimina três elementos na composição do insulto: o insultador, aquele que profere o insulto contra outrem; o insultado, aquele que recebe o insulto; e o insulto propriamente dito, que pode se manifestar como uma palavra, uma atitude, um gesto, uma ação, incluindo seu resultado (Dal Corno, 2010).

Assim, em consonância com as colocações feitas, realçamos que o insulto, que vamos a seguir ilustrar, afasta-se da concepção linguística e se aproxima do tipo de violência suplementar presente na contemporaneidade, desfazendo os efeitos simbólicos produzidos pela violência estrutural, ou seja, desfazendo os limites instituídos pela palavra, o vazio que ela comporta, ou melhor, dissolvendo a palavra.

${ }^{2}$ (...) nous pensons avoir à faire à une violence hors conflit, à une violence qui ne naîtrait pas tant d'un affrontement qu'elle ne résulterait de l'évitement, voire de l'impossibilité d'une confrontation. (Lebrun, 2002, http.//www.freud-lacan.com/articles/articlephp ? id_article=00418)

${ }^{3}$ Esta frase de Lacan constitui a epígrafe do artigo de Lebrun, Une logique d'Enfer (Uma lógica infernal), que consiste em uma das nossas principais referências para este artigo. 
R E V I $S$ S T A

LATINOAMERICANA

DE PSICOPATOLOGIA

F U N D A E N T A L

\section{Refletindo sobre um exemplo de carência da palavra}

A situação que nos impulsionou a escrever este trabalho, isto é, a situação concernente a querelas entre lavadores de carro que eram acompanhadas por palavrões insultuosos os quais, dissemos, eram vociferados. A escolha do termo vociferados em lugar de pronunciados deve-se à forma com que eles eram emitidos. A cada palavrão, o tom ia aumentando, acompanhado pela agitação corporal também crescente. Os intervalos entre as palavras iam, paulatinamente, desaparecendo, de modo que, num dado momento, esses intervalos já não mais existiam, sendo impossível distinguir uma palavra da outra. O sentido, portanto, apagava-se, podendo-se escutar, apenas, uma massa sonora, expressão que Frej (2005) empregou para descrever o caso de uma criança que apresentava grave obstáculo em sua constituição subjetiva. A palavra perdia, assim, sua função de conter/substituir o ato, e os envolvidos se precipitavam uns contra outros para briga corporal, ou lançavam pedaços de pau ou pedras.

Nesse relato muito rápido, destacamos a agitação/excitação corporal que, num crescendo, tornava-se cada vez mais visível, à proporção que o tom dos palavrões aumentava. Dizendo de outro modo, o que nos chamava a atenção, naquele momento, era o fato de que, quanto mais a palavra se dissolvia, maior visibilidade o corpo adquiria. Lembremos a definição de pulsão que, a partir da concepção freudiana, Lacan (1985) formula: a pulsão é o eco no corpo do fato de haver significante.

Indagamos, então: durante a escuta da massa sonora, não se trataria de um corpo, ou de corpos não capturados na linguagem, isto é, de corpos fora do sentido, nos quais o eco significante teria, naquele instante, silenciado? Formulando com outros termos: não se trataria de corpos nos quais a palavra, ao ser dissolvida, teria perdido seu poder de contenção, de limite, por meio do simbólico, do ódio que nos habita, conforme discutido antes?

Segundo Leite (2003), o corpo pulsional é um corpolinguagem escrito como uma só palavra, na impossibilidade de separá-la em dois termos: corpo e linguagem. Essa autora fala, contudo, numa oposição quando coloca: "de um lado, um corpo tomado na face proposicional do sentido, quer dizer na vertente do significante (...) e, de outro lado, a face real, do fora do sentido" (p. 88). No entanto, como se trata de faces do corpo, embora opostas, elas coexistem.

A esse respeito, invocamos a noção freudiana de Aufhebung que, de acordo com o que Frej (2003) demonstrou, explica o movimento de criação de novos espaços psíquicos.

A Aufhebung é um termo da língua alemã - encontrado por Frej, ao longo de toda obra de Freud, e que concerne a momentos nos quais fronteiras e lugares 


\section{ARTIGOS}

na vida humana são delimitados. Trata-se, assim, de um termo que possibilita a apreensão da dimensão do movimento da energia que atravessa o psiquismo e de sua passagem no organismo, considerado desde o momento no qual prevalece o inorgânico que será suprassumido (aufgehoben), desdobrando-se em órgão, organismo, corpo, situados na sociedade e na cultura, inscrevendo o aparelho psíquico. Ao acompanhar o desenrolar do pensamento de Freud, ao abordar essas questões, a autora supracitada afirma que essas instâncias constituem lugares com fronteiras não nitidamente delimitadas, e que coexistem em seu funcionamento simultâneo.

Assim, a massa sonora a que nos referimos estaria nos remetendo a um lugar em que predominam os movimentos corporais (espontâneos) da criança e um contínuo sonoro ainda sem intervalos e sem endereçamento. Esse é o lugar, ou instância do não interdito simbólico, cujo funcionamento estaria prevalecendo, na situação relatada — embora de um modo diferente do que ocorre na criança —, pela ruptura dos limites da palavra.

Nessa perspectiva, colocamos em questão o emprego do termo insulto, isto é, indagamos se ainda poderíamos falar de insulto na referida situação (e em situações semelhantes), posto que, inversamente ao que propôs Freud, em vez de fazer fronteira, de suprassumir o ato violento, a palavra, gradualmente, tornou-se o próprio ato.

\section{Mais algumas palavras}

A título de continuarmos nossa reflexão, recorremos a um exemplo semelhante no que concerne à ruptura da interdição instaurada pela palavra. Trata-se de um chiste analisado por Freud (1893/2006a):

O médico, a cujos cuidados se confiou a Baronesa em sua gravidez, anunciou que ainda não chegara o momento de dar à luz e sugeriu ao Barão que enquanto esperavam jogassem cartas no cômodo vizinho. Após um momento, um grito de dor da Baronesa feriu os ouvidos dos dois homens: "Ah, mon Dieu, que je souffre!" Seu marido levantou-se de um salto, mas o médico fez-lhe sinal que se assentasse: "Não é nada. Vamos continuar com o jogo!" Pouco depois, novos brados da mulher grávida: "Mein Gott, mein Gott, que dores terríveis?" - "Não vai entrar, Professor?", perguntou o Barão. "Não, não. Ainda não é a hora." Finalmente chegou da porta próxima um inconfundível grito de "Ai, ai, ai!". O doutor largou as cartas e exclamou: "Agora é a hora". (p. 45)

Este bem-sucedido chiste demonstra duas coisas pela modificação gradual do caráter dos gritos de dor emitidos, por uma aristocrática dama, na hora do parto: 
mostra, de um lado, como a dor faz com que a natureza primitiva irrompa entre as diversas camadas de verniz de educação e, de outro lado, como uma decisão importante pode ser, adequadamente, tomada na dependência de um fenômeno, aparentemente, comum.

Podemos dizer que a decisão do médico, nesse chiste, estaria condensando a seguinte proposta: é quando a palavra perde seu poder de limitar os movimentos do corpo, que tais movimentos (no caso de contração/dilatação e expulsão) se intensificam, prevalecendo aí, a ordem própria ao organismo que está na nossa origem. Retornamos aqui ao que Frej (2003) demonstrou ao longo da sua tese de doutorado: Freud emprega o termo Aufhebung no momento onde o organismo humano é elevado à condição de sujeito, sem por isso desaparecer, o que implica a convivência das três instâncias: organismo, corpo-linguagem e psiquismo.

Como consequência, propomos que a situação relatada antes e a ilustração por meio do chiste apontam para a possibilidade, sempre presente, de voltarmos, em um dado momento, à condição primeira da nossa existência. Mas, o que nos preocupa é que, nos dias de hoje, situações como aquelas são cada vez mais frequentes (independente de classe social) e, ao que parece, não se restringem ao Brasil, o que aponta para a crise da cultura e da civilização.

Encerramos, enfim, com a exclamação de Dufour, para quem nós vivemos em um mundo, cada vez mais, sadiano.

"Sade não está morto. Mais que isso: ressuscitou. E ainda mais: triunfante!" (Dufour, 2009, p. 13; tradução livre).

Agradecimentos: Agradecemos a nossa colega Nanette Zmeri Frej pela discussão produtiva sobre o tema abordado neste artigo, o que permitiu o avanço de nossas reflexões.

\section{Referências}

Agamben, G. (2002). Homor sacer: o poder soberano e a vida nua. Belo Horizonte: UFMG.

Agamben, G. (2004). Estado de exceção. São Paulo: Boitempo.

Agamben, G. (2009). O que é contemporâneo e outros ensaios. Chapecó: Editora Argos.

Bauman, Z. (2001). Modernidade líquida. Rio de Janeiro: Jorge Zahar.

Bauman, Z. (2003). Comunidade: a busca por segurança no mundo atual. Rio de Janeiro: Jorge Zahar.

Bauman, Z. (2009). Arte da vida. Rio de janeiro: Jorge Zahar.

Bergès, J. \& Balbo, G. (2001). A atualidade das teorias sexuais infantis. Porto Alegre: CMC Editora. 


\section{ARTIGOS}

Bergès, J. \& Balbo, G. (2002). Jogo de posições da mãe e da criança. Ensaio sobre o transitivismo. Porto Alegre: CMC Editora.

Buarque de Holanda, S. (2009). Raízes do Brasil. São Paulo: Companhia das Letras.

Dal Corno, G.O.M. (2010). De paus e pedras a palavras: breve investigação sobre o insulto como linguagem disfêmica. Revista Trama, 6(12), 39-49, $2^{\circ}$ semestre de 2010.

Didier Weill, A. (1999). Invocações: Dionísio, Moisés, São Paulo e Freud. Rio de Janeiro: Cia. de Freud.

Dufour, D-R. (2007). Le divin marché. Paris: Denöel.

Dufour, D-R. (2009). La cité perverse: sadisme et pornographie. Paris: Denöel.

Frej, N.Z. (2003). Le don du nom et son empêchement. Au sujet des enfants de rue au Brésil. Tese de Doutorado, Université - Paris Nord (Paris XIII). U.F.R. Des Lettres, des Sciences de l'Homme et des Sociétés.

Frej, N. Z. (2005, setembro). Entre a criança e a mãe: a língua estrangeira. $1^{\circ}$ Encontro Nordestino em Aquisição da Linguagem. Recife, Universidade Católica de Pernambuco.

Freud, S. (2006a). Sobre o mecanismo psíquico dos fenômenos histéricos: uma conferência. In Obras Completas de Sigmund Freud. (Vol. III). Rio de Janeiro: Imago. (Trabalho original publicado em 1893).

Freud, S. (2006b). Os chistes e sua relação com o inconsciente. In Obras Completas de Sigmund Freud. (Vol. VIII). Rio de Janeiro: Imago. (Trabalho original publicado em 1905).

Houaiss, A. (2008). Mini Houaiss. Dicionário da língua portuguesa. Rio de Janeiro: Objetiva, 2008. p. 427.

Laberge, J. (2008). Que bebê alienado! In E. Oliveira et al. As interfaces da clínica com bebês. Recife: Ninar. p. 197-204.

Lacan, J. (1975). Le symptôme. Conferência pronunciada no Centre Raymond de SaussureGenebra, 4 de outubro de 1975. Organizada pela Société suisse de psychanalyse. Recuperado em 10 jun.2013 de: <http://www.ecole-lacanienne.net/bibliotheque.php?id=10>.

Lacan, J. (1985). O seminário. Livro 11. Os quatro conceitos fundamentais da psicanálise. Rio de Janeiro: Jorge Zahar. (Trabalho original publicado em 1964).

Lebrun J-P. (2002). Une logique d'enfer. Recuperado em 12 ago.2013 de: <http.//www.freud-lacan. com/articles/articlephp? id_article=00418>.

Lebrun, J-P. (2008). O futuro do ódio. Porto Alegre: CMC Editora.

Lebrun, J-P. (2010). O mal-estar na subjetivação. Porto Alegre: CMC Editora.

Leite, N. V. A. Riso e rubor: para falar do corpolinguagem. In N.V.A. Leite (Org.). Corpolinguagem: gestos e afetos. Campinas: Mercado de Letras, 2003. p. 81-92.

Lemos, C. T. G. (2008). Da angústia na infância. Revista Literal, n.10, 117-126.

Pinker, S. (2008). Do que é feito o pensamento: a língua como janela para a natureza humana. São Paulo: Companhia das Letras. 


\section{Resumos}

(Body language and the unlimited boundaries of the word in the insult)

As starting point for this article, we take the concept of structural violence (Lebrun, 2002), i.e., the violence of language that constitutes us as human beings. In the contemporary world, the denial of such violence has produced an additional kind of violence, which necessarily involves the deficit of the word. The analysis of a situation - a quarrel between car washers - provided indications on the manner of operation of the additional violence, undoing the symbolic effects produced by structural violence, i.e., undoing the limits imposed by language.

Key words: Language, insult, structural violence, deficit of the language

(Corpslangage et le non-limite de la parole dans l'insulte)

Cet article a pour point de départ le concept de la violence structurelle (Lebrun, 2002), soit, la violence du langage qui nous constitue en tant qu'êtres humains. Dans le monde contemporain, la négation de ce type de violence a produit une violence supplémentaire qui implique nécessairement l'absence de la parole. L'analyse d'une situation - une querelle entre des laveurs de voitures - nous a fourni des indications sur une des façons d'agir de la violence supplémentaire. Celle-ci annule les effets symboliques produits par la violence structurelle, soit, elle défait les limites établies par le langage.

Mots clés: Langage, insultes, violence structurale, manque de langage

(Cuerpo-lenguaje y lo ilimitado de la palabra en el insulto)

Este artículo toma como punto de partida el concepto de violencia estructural (Lebrun, 2002), es decir, la violencia del lenguaje que nos constituye como seres humanos. En el mundo contemporáneo, la negación de este tipo de violencia produjo una forma suplementar que, necesariamente, pasa, necesariamente, por la carencia de la palabra. El análisis de una situación - una reyerta entre unos limpiadores de coches - proporcionó indicaciones sobre una forma de puesta en acto suplementar que deshacen los efectos simbólicos producidos por la violencia estructural, esto es, descomponiendo los límites instituidos por el lenguaje.

Palabras clave: Lenguaje, insulto, violencia estructural, carencia del lenguaje

(Körpersprache und die Grenzenlosigkeit des Wortes bei Beschimpfungen)

Der Begriff der strukturellen Gewalt (Lebrun, 2002), bzw. die Gewalt der Sprache, die uns als menschliche Wesen auszeichnet, ist der Ausgangspunkt dieses Beitrags. Die Verleugnung dieser Art von Gewalt hat in der heutigen Welt eine zusätzliche Gewalt hervorgebracht, welche sich zwangsläufig durch den Wortmangel 


\section{ARTIGOS}

ergibt. Die Untersuchung einer Situation - einem Streit zwischen Autowäschern lieferte Angaben zu einer Wirkungsart der zusätzlichen Gewalt, welche die durch die strukturelle Gewalt hervorgerufenen symbolischen Auswirkungen, $d . h$. die durch die Sprache gesetzten Grenzen, auföst.

Schlüsselwörter: Sprache, Beschimpfung, strukturelle Gewalt, Wortmangel

Cet article traite de l'univers inconscient des sculptures de l'artiste brésilien

Citação/Citation: Carvalho, G.M.M.de \& Melo, M. de F.V. de (2014, setembro). Um sujeito no mercado das pílulas. Revista Latinoamericana de Psicopatologia Fundamental, 17(3-Suppl.), 626-637.

Editor do artigo/Editor: Prof. Dr. Manoel Tosta Berlinck

Recebido/Received: 15.3.2014/ 3.15.2014 Aceito/Accepted: 10.4.2014 / 4.10.2014

Copyright: (C) 2009 Associação Universitária de Pesquisa em Psicopatologia Fundamental/ University Association for Research in Fundamental Psychopathology. Este é um artigo de livre acesso, que permite uso irrestrito, distribuição e reprodução em qualquer meio, desde que o autor e a fonte sejam citados / This is an open-access article, which permits unrestricted use, distribution, and reproduction in any medium, provided the original author and source are credited.

Financiamento/Funding: As autoras declaram não ter sido financiadas ou apoiadas / The authors have no support or funding to report.

Conflito de interesses/Conflict of interest: As autoras declaram que não há conflito de interesses / The authors have no conflict of interest to declare.

\section{Glória Maria Monteiro de Carvalho}

Doutora em Linguística pela Universidade Estadual de Campinas - Instituto de Estudos da Linguagem-IEL/Unicamp (Campinas, SP, Br); Professora e pesquisadora CNPq do Programa de Pós-graduação em Ciências da Linguagem da Universidade Católica de Pernambuco Unicap (Recife, PE, Br), na área de aquisição de linguagem.

Rua General Abreu e Lima, 239/1801 - Tamarineira

52041-040 Recife, PE, Br.

e-mail: gmmcarvalho@uol.com.br

\section{Maria de Fátima Vilar de Melo}

Doutora em Psicologia pela Université René Descartes - Paris V - Sorbonne (Paris, França); Professora Pesquisadora do curso de Psicologia e do Programa de Pós-Graduação em Ciências da Linguagem da Universidade Católica de Pernambuco - Unicap (Recife, PE, Br). Rua Guilherme Pinto, 50/1001 - Graças 52011-210 Recife, PE, Br.

e-mail: mfvmelo@uol.com.br 